\title{
Implantação da Lei 11.738/2008 - Lei do Piso - na Rede Municipal de Ensino de Feira de Santana: A Dimensão do Planejamento na Gestão Pública
}

\author{
Marcos da Silva da Rosa ${ }^{1}$
}

Resumo: O presente artigo tem por objetivo apresentar o processo de implantação da reserva de carga horaria para atividade extraclasse dos professores do magistério público do município de Feira de Santana, por determinação da lei 11.738/2008 (Lei do Piso). Para tanto, além do relato das ações da gestão municipal visando adequação à lei, também será analisada a pertinência e validade dessas ações, a luz dos conceitos do Planejamento na Gestão Público.

Palavras chave: Educação; Lei do Piso; Planejamento.

\section{Implementation of Law 11.738 / 2008 - Floor Law - in the Municipal Network of Education of Feira de Santana: The Dimension of Planning in Public Management}

\begin{abstract}
This article aims to present the process of implementation of the reserve of hours for extraclass activity of teachers of the public teaching profession of the municipality of Feira de Santana, by determination of law 11.738 / 2008 (The Floor Law). Therefore, besides the report of the actions of the municipal management aiming to adapt to the law, will also be analyzed the pertinence and validity of these actions, in light of the concepts of Public Management Planning.
\end{abstract}

Keywords: Education; Floor Law; Planning.

\section{Introdução}

O Direito a Educação está garantido na Constituição Federal de 1988, precisamente em seus artigos 205 e 206, capítulo III "Da educação, da cultura e do desporto". Diz o texto constitucional:

Art. 205. A educação, direito de todos e dever do Estado e da família, será promovida e incentivada com a colaboração da sociedade, visando ao pleno desenvolvimento da pessoa, seu preparo para o exercício da cidadania e sua qualificação para o trabalho.

\footnotetext{
${ }^{1}$ Professor da Rede Municipal de Ensino de Feira de Santana-Ba. Graduado em História (UNEB), Direito(UEFS), pósgraduado em Filosofia Contemporânea (UEFS), Ensino de Filosofia (UFBA), Especializando em Gestão Pública Municipal (UNIVASF). Contato: professormarcosrosa@gmail.com.
}

15 Id on Line Rev. Mult. Psic. V.12, N. 41, p.15-30, 2018 - ISSN 1981-1179

Edição eletrônica em http://idonline.emnuvens.com.br/id 
Art. 206. O ensino será ministrado com base nos seguintes princípios:

I - Igualdade de condições para o acesso e permanência na escola;

II - Liberdade de aprender, ensinar, pesquisar e divulgar o pensamento, a arte e o saber;

III - pluralismo de ideias e de concepções pedagógicas, e coexistência de instituições públicas e privadas de ensino;

IV - Gratuidade do ensino público em estabelecimentos oficiais;

V - valorização dos profissionais da educação escolar, garantidos, na forma da lei, planos de carreira, com ingresso exclusivamente por concurso público de provas e títulos, aos das redes públicas; (Redação dada pela Emenda Constitucional no 53 , de 2006)

VI - Gestão democrática do ensino público, na forma da lei;

VII - Garantia de padrão de qualidade.

VIII - Piso salarial profissional nacional para os profissionais da educação escolar pública, nos termos de lei federal. (Incluído pela Emenda Constitucional $\mathrm{n}^{\circ} 53$, de 2006)

Parágrafo único. A lei disporá sobre as categorias de trabalhadores considerados profissionais da educação básica e sobre a fixação de prazo para a elaboração ou adequação de seus planos de carreira, no âmbito da União, dos Estados, do Distrito Federal e dos Municípios. (Incluído pela Emenda Constitucional n 53, de 2006).

Outros ordenamentos jurídicos também traduzem a relação de obrigações do Estado para com a educação pública. A Lei 9.394/1996, Lei de Diretrizes e Bases da Educação, por exemplo, apresenta em seu artigo $2^{\circ}$ :

Art. $2^{\circ}$ A educação, dever da família e do Estado, inspirada nos princípios de liberdade e nos ideais de solidariedade humana, tem por finalidade o pleno desenvolvimento do educando, seu preparo para o exercício da cidadania e sua qualificação para o trabalho.

E em seu artigo 67 realça a importância da valorização da melhor condição de trabalho do professor, vejamos:

Art. 67. Os sistemas de ensino promoverão a valorização dos profissionais da educação, assegurando-lhes, inclusive nos termos dos estatutos e dos planos de carreira do magistério público:

I - ingresso exclusivamente por concurso público de provas e títulos;

II - aperfeiçoamento profissional continuado, inclusive com licenciamento periódico remunerado para esse fim;

III - piso salarial profissional;

IV - progressão funcional baseada na titulação ou habilitação, e na avaliação do desempenho;

V - período reservado a estudos, planejamento e avaliação, incluído na carga de trabalho;

VI - condições adequadas de trabalho.

Logo, é possível perceber que não há ineditismo na Lei do Piso, salvo o estabelecimento de valor mínimo para a remuneração dos professores, pois a necessidade de condição de 
trabalho adequada, inclusive com tempo dedicado ao planejamento, estudo e avaliação já estavam previstos desde na Lei de Diretrizes e bases da Educação, desde o ano de 1996.

Ainda no contexto do arcabouço legal pátrio, é possível destacar a lei nº 8.069/1990 (Estatuto da Criança e do Adolescente). O fato do ponto central dessa lei ser a garantia dos direitos da criança e do adolescente, remete grande importância a educação, senão vejamos trechos dos artigos 53 e 54:

Art. 53. A criança e o adolescente têm direito à educação, visando ao pleno desenvolvimento de sua pessoa, preparo para o exercício da cidadania e qualificação para o trabalho, assegurando-se-lhes:

(...)

V - acesso à escola pública e gratuita próxima de sua residência.

Art. 54. É dever do Estado assegurar à criança e ao adolescente:

I - ensino fundamental, obrigatório e gratuito, inclusive para os que a ele não tiveram acesso na idade própria;

II - progressiva extensão da obrigatoriedade e gratuidade ao ensino médio;

III - atendimento educacional especializado aos portadores de deficiência, preferencialmente na rede regular de ensino;

IV - atendimento em creche e pré-escola às crianças de zero a seis anos de idade;

IV - atendimento em creche e pré-escola às crianças de zero a cinco anos de idade; (Redação dada pela Lei $n^{\circ} 13.306$, de 2016)

V - acesso aos níveis mais elevados do ensino, da pesquisa e da criação artística, segundo a capacidade de cada um;

VI - oferta de ensino noturno regular, adequado às condições do adolescente trabalhador;

VII - atendimento no ensino fundamental, através de programas suplementares de material didático-escolar, transporte, alimentação e assistência à saúde.

$\S 1^{\circ} \mathrm{O}$ acesso ao ensino obrigatório e gratuito é direito público subjetivo.

$\S 2^{\circ} \mathrm{O}$ não oferecimento do ensino obrigatório pelo poder público ou sua oferta irregular importa responsabilidade da autoridade competente.

$\S 3^{\circ}$ Compete ao poder público recensear os educandos no ensino fundamental, fazerlhes a chamada e zelar, junto aos pais ou responsável, pela frequiência à escola.

Assim, não resta dúvida quanto ao papel do estado na dupla obrigação: oferecer e garantir o ensino gratuito à crianças e adolescentes e, por outro lado, garantir condições mínimas de trabalho aos professores, tanto salariais, quanto de jornada de trabalho.

A manutenção financeira dessas obrigações legais está prevista na Lei n ${ }^{\circ} 11.494 / 2007$ que cria o Fundo de Manutenção e Desenvolvimento da Educação Básica e de Valorização dos Profissionais da Educação (FUNDEB), em substituição ao Fundo de Manutenção e Desenvolvimento do Ensino Fundamental e de Valorização do Magistério (FUNDEF).

O FUNDEB tem por objetivo financiar a educação básica nacional, através da contribuição dos seus entes federativos, por meio da arrecadação de impostos. O recurso retorna a esses entes através da contabilização dos alunos matriculados. Senão vejamos: 
Art. 1o É instituído, no âmbito de cada Estado e do Distrito Federal, um Fundo de Manutenção e Desenvolvimento da Educação Básica e de Valorização dos Profissionais da Educação - FUNDEB, de natureza contábil, nos termos do art. 60 do Ato das Disposições Constitucionais Transitórias - ADCT.

Parágrafo único. A instituição dos Fundos previstos no caput deste artigo e a aplicação de seus recursos não isentam os Estados, o Distrito Federal e os Municípios da obrigatoriedade da aplicação na manutenção e no desenvolvimento do ensino, na forma prevista no art. 212 da Constituição Federal e no inciso VI do caput e parágrafo único do art. 10 e no inciso I do caput do art. 11 da Lei ${ }^{\circ}$ 9.394, de 20 de dezembro de 1996, de:

I - pelo menos $5 \%$ (cinco por cento) do montante dos impostos e transferências que compõem a cesta de recursos do Fundeb, a que se referem os incisos I a IX do caput e o $\S 1$ o do art. 3o desta Lei, de modo que os recursos previstos no art. 3o desta Lei somados aos referidos neste inciso garantam a aplicação do mínimo de $25 \%$ (vinte e cinco por cento) desses impostos e transferências em favor da manutenção e desenvolvimento do ensino;

II - pelo menos $25 \%$ (vinte e cinco por cento) dos demais impostos e transferências.

Art. 2o Os Fundos destinam-se à manutenção e ao desenvolvimento da educação básica pública e à valorização dos trabalhadores em educação, incluindo sua condigna remuneração, observado o disposto nesta Lei.

$\mathrm{O}$ Artigo $2^{\circ}$ da presente lei recebe reforço quando combinado com o artigo 22, que determina que $60 \%$ dos recursos transferidos aos Estados e Municípios devem, obrigatoriamente, ser destinados a folha de pagamento dos profissionais da educação:

Art. 22. Pelo menos $60 \%$ (sessenta por cento) dos recursos anuais totais dos Fundos serão destinados ao pagamento da remuneração dos profissionais do magistério da educação básica em efetivo exercício na rede pública.

Parágrafo único. Para os fins do disposto no caput deste artigo, considera-se:

I - remuneração: o total de pagamentos devidos aos profissionais do magistério da educação, em decorrência do efetivo exercício em cargo, emprego ou função, integrantes da estrutura, quadro ou tabela de servidores do Estado, Distrito Federal ou Município, conforme o caso, inclusive os encargos sociais incidentes;

II - profissionais do magistério da educação: docentes, profissionais que oferecem suporte pedagógico direto ao exercício da docência: direção ou administração escolar, planejamento, inspeção, supervisão, orientação educacional e coordenação pedagógica;

III - efetivo exercício: atuação efetiva no desempenho das atividades de magistério previstas no inciso II deste parágrafo associada à sua regular vinculação contratual, temporária ou estatutária, com o ente governamental que o remunera, não sendo descaracterizado por eventuais afastamentos temporários previstos em lei, com ônus para o empregador, que não impliquem rompimento da relação jurídica existente.

Portanto, antes mesmo da promulgação da lei 11.738/2008 o ordenamento jurídico brasileiro já indicava a necessidade de valorização dos profissionais da educação e garantia da universalização e qualidade do ensino. A Lei do Piso, seria a culminância de um processo que, pelo menos na perspectiva histórica mais recente, teria iniciado com a Constituição Federal de 1988. 
Garantir condições materiais para o desenvolvimento da educação é obrigação fundamental para o gestor público, e o legislador, através da Lei do Piso, apresentou os parâmetros e limites para o estabelecimento dessas condições materiais.

A implantação da Lei do Piso no país não ocorreu de modo automático e imediato após sua promulgação. Foram necessárias algumas ações judiciais e greves de professores para a sua efetivação. Assim, ainda que tenha sido uma implantação lenta e gradual é possível perceber avanços significativos na melhoria da condição de trabalho dos professores da rede pública, principalmente naqueles municípios com menor arrecadação financeira e poder econômico.

Assim, assegurar um piso salarial mínimo e especificar jornada de trabalho para as atividades extraclasse configura expressivo avanço não apenas normativo, mas da vida prática dos profissionais da educação pública brasileira.

\section{A Lei 11.738/2008}

$\mathrm{Na}$ esteira de normativos importantes para a educação pública nacional, como a Lei 11.494/2007, que institui o FUNDEB, a Lei 9.934/1996, (Lei de Diretrizes e Bases da Educação) e, em certa medida a Lei 8.069/1990 (Estatuto da Criança e do Adolescente), a Lei do Piso é um marco legal na regulamentação salarial e jornada de trabalho dos profissionais do magistério público.

Sancionada em 2008 a lei possui poucos artigos, precisamente oito. Porém, dentre outras regulamentações, definiu um piso salarial mínimo a ser instituído em todo território nacional, que atualmente é $\mathrm{R} \$ 2.455,35$ para uma jornada de 40 horas semanais, como também regulamentou a disposição de carga horária a ser dedicada ao planejamento, formação e avaliação, ou seja, atividade extraclasse, que passou a ser de no mínimo 1/3 da carga horária.

Conforme já anunciado, a aplicação da Lei do Piso não aconteceu sem resistência por parte dos entes federativos. Municípios e Estados propuseram seguidas ações judiciais com intuito de torná-la inconstitucional. Uma Ação Direta de Inconstitucionalidade, a ADIN n ${ }^{\circ}$ 4167, foi impetrada pelos governos estaduais de Mato Grosso do Sul, Rio Grande do Sul, Paraná, Ceará e Santa Catarina, ainda no ano de 2008. Sendo superada por decisão definitiva do Supremo Tribunal Federal em julgamento ocorrido em abril de 2011, declarando-a plenamente constitucional. 
A partir de então muitos estados e municípios passaram a se organizar com objetivo de implantar a lei. No que diz respeito a sua efetivação, a maior dificuldade para os municípios não reside apenas no reajuste do mínimo remuneratório, mas principalmente na garantia da reserva de carga horária para avaliação, planejamento e estudos. Isto porque o artigo $2^{\circ}$, da Lei do Piso estabelece que pelo menos $1 / 3$ da carga horária do professor deve ser dedicada a atividades extraclasse, o que significa uma ampliação aproximada de $40 \%$ do seu contingente de professores, pois aqueles contratados para substituir os professores que garantiram a reserva de carga horária, também terão direito a essa reserva.

O conselho Nacional de Educação (CNE), órgão ligado ao Ministério da Educação, em estudo sobre a Lei do Piso, apresenta conceitos e limites ao horário destinado às atividades extraclasses, seriam:

ESTUDO: investir na formação contínua, graduação para quem tem nível médio, pósgradução para quem é graduado, mestrado, doutorado. Sem falar nos cursos de curta duração que permitirão a carreira horizontal. Sem formação contínua o servidor estagnará no tempo quanto à qualidade e efetividade do trabalho, o que comprometerá a qualidade da Educação, que é direito social e humano fundamental;

PLANEJAMENTO: planejar adequadamente as aulas, o que é relevante para o ensino; AVALIAÇÃO: Correção de provas, redações, acompanhamento do processo ensinoaprendizagem, tais como entrevistas com o aluno. Não é justo nem correto que o professor trabalhe em casa, fora da jornada, sem ser remunerado, corrigindo centenas de provas, redações e outros trabalhos. (Estudo Sobre a Lei do piso CNE, p.8)

Assim, o adequado ajuste ao presente ordenamento jurídico implica não somente em garantir o pagamento do piso salarial, mas também reserva a carga horária mínima para atividades extraclasse. O que significa, portanto, ampliar significativamente o investimento na educação através da contratação de professores.

Detalhando a composição da jornada de trabalho do professor, a partir da Lei do Piso, surgem dois novos conceitos: o Horário de Trabalho Pedagógico em Local de Livre Escolha, que é aquele destinado ao planejamento, avaliação e estudo, em que não há interação com estudante. E pode acontecer em qualquer espaço de livre escolha do docente. Equivale a $50 \%$ da carga horária disposta para a atividade extraclasse.

E o Horário de Trabalho Pedagógico Coletivo, que é aquele destinado as discussões sobre o planejamento pedagógico coletivo, também não envolve interação com o estudante. Geralmente é quando ocorre o planejamento das atividades semanal dos docentes, coletivamente na unidade escolar, ou em encontros promovidos pela Secretaria de Educação. Equivale aos $50 \%$ restantes da carga horária disposta para a atividade extraclasse. 
A título de exemplo, o professor com jornada semanal de 40 horas, teria a seguinte disposição de horários: 28 horas de interação direta com estudantes; e 12 hora destinadas ao planejamento estudo e avaliação, sendo que estas estariam assim subdivididas: 6 horas destinadas ao trabalho coletivo na unidade escolar ou local indicado pela secretaria de educação, e as outras 6 horas semanais a disposição do professor, em local de livre escolha, conforme recomendação do Conselho Nacional de Educação.

Assim, a normatização de um piso remuneratório mínimo e uma carga horária remunerada para o professor desenvolver suas atividades extraclasses, tanto demonstra a intenção e valorização de uma educação pública e universal, por parte da sociedade brasileira, como também, por outro lado, evidencia a resistência de gestores públicos, principalmente nos municípios, sob a justificativa da insuficiência de recursos financeiros.

E o processo de implantação da Lei do Piso na rede municipal de ensino de Feira de Santana põe em destaque exatamente esse processo de diálogo entre gestores públicos e professores, com momentos de avanços e conquistas e outros de resistências e recuos.

\section{O Planejamento para a implantação da Lei do Piso em Feira de Santana}

Situada a 108 quilômetros de Salvador, capital do Estado da Bahia, a qual se liga através da BR-324, Feira de Santana é a maior cidade do interior das regiões Norte, Nordeste, Centro Oeste e Sul do Brasil. Sua população é de 627.477 habitantes (Instituto Brasileiro de Geografia e Estatística - IBGE, 2017).

Está localizada no principal entroncamento rodoviário do Norte-Nordeste brasileiro (BRs 101, 116 e 324 e rodovias estaduais), e o segundo do Brasil, atrás apenas de São Paulo. É passagem obrigatória para o tráfego oriundo do Sul, Sudeste e do Centro-Oeste, e para quem se dirige a Salvador e outras capitais e cidades nordestinas.

Possui o $69^{\circ}$ maior produto interno bruto (PIB) municipal do Brasil, o terceiro maior na Bahia e o maior do interior do Nordeste. Seu forte comércio pode ser exemplificado a partir da conhecida "Feiraguai", um dos três maiores centros de comércio de produtos piratas e importados do país, perdendo apenas para a 25 de março em São Paulo e a feira do Paraguai em Brasília. 
O Município também se destaca na educação básica particular, possuindo grande quantidade de colégios, e no ensino superior, pois é sede da Universidade Estadual de Feira de Santana (UEFS), e possui outras 30 Faculdades particulares, além de um campus da Universidade Federal do Recôncavo da Bahia (UFRB). Conta também com instituições de educação tecnológica como o Instituto Federal da Bahia (IFBA) e o Centro de Educação Tecnológica do Estado da Bahia (CETEB).

Possui uma rede pública municipal de ensino com 217 escolas, sendo 25 creches, e 192 escolas de ensino infantil e fundamental. E ainda, aproximadamente 45 mil alunos e 1.539 professores. A rede está integrada em forma de sistema, conforme apregoa o artigo 11 da Lei 9.9394/1996 (Lei de Diretrizes e bases da Educação), consubstanciada na lei municipal $3.388 / 2013$.

Apesar da Lei 11.738 ter sido promulgada em 2008, apenas em 2014 teve início a discussão quanto a implantação da reserva de carga horária para atividades extraclasses, conforme exigência do seu art. $2^{\circ}$, parágrafo $4^{\circ}$. Ainda que o piso salarial, outra determinação da lei, já tenha sido garantido pelos professores da rede anos antes.

Após negociações entre os professores, através do sindicato, e a gestão municipal, foi estabelecido o plano para a adequação à lei. A seguir serão apontadas as principais ações da gestão municipal com fim de atender o mandamento legal, e em seguida confrontaremos com as orientações conceituais que regem o conceito de Planejamento na Administração Pública.

\section{Criação de Comissão representativa}

A formalização das ações da Administração Municipal teve início a partir da publicação do Decreto $\mathrm{n}^{\circ}$ 9.234/14, em 15 de maio de 2014, criando comissão multirepresentativa para discutir a aplicação da Lei do Piso no município de Feira de Santana.

Compôs a Comissão as seguintes representações: Secretaria Municipal de Educação; Procuradoria Geral do Município; Secretaria Municipal de Administração; Secretaria Municipal da Fazenda; Conselho Municipal de Educação; Sindicato dos Trabalhadores em Educação da Bahia - APLB. Cada representante, a partir das exigências e necessidades de sua secretaria ou entidade, contribuiria para a elaboração de um planejamento para a devida adequação à Lei do Piso. 
Segundo o art. $3^{\circ}$ do mencionado decreto, a Comissão tinha os seguintes objetivos:

I - Mobilizar ações de pesquisa para implementação da "Lei do Piso" através de aplicação proporcional da referida norma.

II- Instrumentalizar meios de informação e orientação sobre a aplicação da norma aos casos concretos.

III - propor mecanismos para adequar as necessidades à realidade local, objetivando maior eficiência e eficácia na interpretação e aplicação da legislação vigente.

IV Compreender condições de atender a demanda existente, a fim de garantir uniformidade, padronização e segurança no sistema de modo a garantir a adequada remuneração com a jornada de trabalho devida aos professores;

$\mathrm{V}$ - Desenvolver outras atividades correlatas.

As reuniões aconteceram entre os meses de junho e outubro de 2014. E ao final do trabalho foi apresentado relatório final ao Poder Executivo com as ações a serem adotadas. Assim, considerando que este foi um documento importante, e que orientou alguma das ações da Administração Municipal, parte daqueles registros serão destacados e analisados nesse artigo.

\section{Experiências em outros municípios e a implantação gradual}

A Comissão realizou consultas a União dos Dirigentes Municipais (UNDIME) com objetivo de conhecer experiências de outros municípios no processo de adequação a Lei do Piso. E, conforme relato, a maioria deles, a exemplo de Cabo Frio (RJ), Prudentópolis (PR), Jacarezinho (PR), Ortigueira (PR) e etc. possuíam cenário distinto de Feira de Santana e não puderam ser considerados como parâmetros. Porém, identificaram que a experiência do município de Campo Grande (MS) poderia ser útil a Feira de Santana, pelo menos no que diz respeito a aplicação gradual da lei. Destacou a Comissão:

[Campo Grande] possui seis mil professores, entre noventa e cem mil alunos, e noventa e seis escolas. Iniciou a implantação da Lei do Piso no ano de 2014 após dois mandatos de debates e preparação. Para tanto a capital sul-mato-grossense contratou aproximadamente mil professores, alterou a matriz curricular: incluiu disciplinas como artes, educação física e ciências (professores com formação em pedagogia) e propôs a adaptação a Lei do Piso de modo gradativo (diminuição de duas aulas por ano). 
Assim, a partir do estudo de outras experiências a comissão teria indicado a Administração Municipal que a opção de implantação gradual seria a mais adequada, considerando sua condição financeira, material e de pessoal.

\section{Levantamento diagnóstico: quantidade de turmas, professores, inclusive aqueles aptos a pedir aposentadoria e necessidade de contratação}

Outra ação da Comissão foi realizar o levantamento da situação da rede municipal de ensino (quantidade de turmas, alunos, professores ativos em regência e em demais funções). Esses dados seriam essenciais para identificar a quantidade de professores que deveriam ser contratados para o cumprimento da lei.

Assim, foram encontrados os seguintes dados: 1.133 turmas (creche, pré-escola, ensino fundamental I e II), 1.539 professores em regência. Sendo necessário, portanto, para adequação a Lei do Piso a contratação de 610 professores. E ainda, que a Administração deveria considerar em seu planejamento aqueles professores que estariam aptos a requerer aposentadoria nos próximos três anos, pois, conforme aponta o relatório, completariam os pré-requisitos legais (idade e tempo de contribuição) e necessários, a saber: 600 professores com 40 horas de carga horária, e 97 professores com 20 horas de carga horária.

\section{Do período reservado as atividades extraclasse}

A Lei estabelece que no mínimo 1/3 da carga horária do professor deve ser disposta para atividades extraclasse, assim, considerando que no município de Feira de Santana a carga horária do professor é de 20 ou 40 hora semanais, a Comissão indicou a quantidade de horas que seriam dedicadas a atividades extraclasse, e ainda realizou consulta aos professores da rede para que esses apontassem as ações que deveriam preencher o tempo laboral dedicado a atividade extraclasse:

É importante destacar que o período reservado para formação, avaliação e planejamento, incluído na carga horária, conforme artigo 67 , Inciso $\mathrm{V}$ da lei $9394 / 2006$ - LDB e regulamentado pela lei $11.738 / 2008$, em seu artigo $2^{\circ}{ }_{\S} 4^{\circ}$, na rede 
municipal de ensino Feira de Santana equivale a: 07 (sete) horas aulas para os professores que possuem vínculo de 20 horas semanais, e 14 horas aulas para aqueles que possuem vínculo de 40 horas semanais (...)

E o resultado da consulta aos professores indicando de que modo deveria ser utilizado o período destinado ao planejamento, estudo e avaliação foi o seguinte:

- Para o período de trabalho coletivo a ser realizado exclusivamente na unidade escolar (3 ou 6 horas/aulas):

1. Atividade com a coordenação

Acompanhamento de planejamento; Elaboração de projetos didáticos; Acompanhamento e avaliação de processos pedagógicos; Estudo, elaboração, acompanhamento, revisão e avaliação do Projeto Político Pedagógico e regimento da unidade escola; Orientação pedagógica; Discussão e elaboração da proposta curricular da unidade escolar; Reuniões e/ou atendimento a família;

Reunião com a comunidade escolar; Conselho de classe por unidade; Formação pedagógica; Avaliação do plano de curso;

2. Formação continuada

Seminários; Debates; Grupos de estudos; Mesas redondas; Oficinas pedagógicas; Formação pedagógica; Fórum; Work shop; Outros.

- Para o período de trabalho individual a ser realizado em local de livre escolha (4 ou 8 horas/aulas):

Formação continuada; Alimentação do sistema digital; Participação em eventos profissionais e culturais; Elaboração e correção de atividades, avaliações e relatórios; Estudo, pesquisa, coleta de dados e produção de materiais pedagógicos; Análise de produção dos alunos.

Ainda como um indicativo de planejamento a ser considerada pela Administração Municipal, a Comissão conclui o relatório indicando as ações a serem adotadas para adequação as exigências da Lei do Piso:

1. Considerar como parâmetro o levantamento do quantitativo de professores necessários para adequação a lei 11.738/2008 realizado por esta Comissão, que teve como realidade o ano letivo de 2014 , tendo em vista a necessidade de realização de concurso público;

2. Racionalizar e manter o acompanhamento das turmas com objetivo de evitar superlotação ou turmas com número de alunos abaixo do que determina a legislação pertinente.

3. Que as Secretarias pertinentes realizam os cálculos necessários com objetivo de incluir no orçamento municipal os gastos com a adequação a lei 11.738/2008;

4. Dar início aos encaminhamentos administrativos pertinentes para realização de concurso público visando à contratação dos professores;

5. Adequar o Plano de Carreira do Professor Municipal a referida Lei Federal;

6. Que a Secretaria Municipal de Educação realize encontros com diretores e coordenadores das escolas municipais com intuito de orientar a organização dos horários escolares das escolas e distribuição da carga horária diante da nova realidade organizacional; 
7. Convocação dos professores aprovado no mencionado concurso público e encaminhamento para as escolas, conforme sua necessidade.

A adequação do Plano de Carreira dos Professores do município foi providenciada, resultando na alteração do artigo 307, parágrafo $7^{\circ}$, da Lei Complementar Municipal 01/1994, que trata da jornada de trabalho do professor, passando a vigorar com a seguinte redação:

$\S 7^{\circ} \mathrm{O}$ Professor do Ensino Fundamental da $1^{\mathrm{a}}$ à $4^{\mathrm{a}}$ série em regência de classe fará jus a uma gratificação de $15 \%$ (quinze por cento) a título de atividades pedagógicas. (Redação dada pela Lei Complementar n 26/2005)

I - De carga horária do Professor de Ensino Fundamental de $1^{\mathrm{a}}$ à $4^{\mathrm{a}}$ série em regência de classe, fixada nas alíneas "a" e "b" deste artigo, 10\% (dez por cento) serão destinados à preparação de atividades pedagógicas, conforme regulamento do Secretaria Municipal de Educação. (Redação acrescida pela Lei no 101/2016)

II - A totalidade do percentual de reserva da carga horária para desempenho de atividades pedagógicas estabelecida na Lei Federal 11.738/08 para o professor do Ensino Fundamental de $1^{\mathrm{a}}$ à $4^{\mathrm{a}}$ série em regência de classe, será implantada a partir de 2017 , com a composição de $10 \%$ (dez por cento) para o primeiro semestre e $15 \%$ (quinze por cento) para o segundo semestre, havendo disposição orçamentária e financeira da municipalidade. (Redação acrescida pela Lei nº 101/2016).

Importante mencionar que ainda em 2018, após negociações com professores e sindicatos a rede municipal ainda estaria implantando a reserva de carga horária, conforme regulamentação da Portaria ${ }^{\circ}$ 05/2018, publicada no diário oficial eletrônico do município em 18 de abril de 2018.

Quanto a contratação de professores, além convocação dos últimos aprovados do concurso realizado em 2013, também foi realizado no ano de 2017 um processo seletivo para contratação em regime temporário. Tendo sido convocados até o ano de 2018, todos os 866 aprovados. E ainda, a Administração Municipal anunciou realização de concurso púbico para contratação e professores efetivos já em 2018.

Assim, é possível perceber que a Comissão representada por diversas secretarias municipais, sindicato e conselho municipal de educação exerceu importante papel na elaboração do planejamento das ações da Administração Municipal, tendo em vista que as sugestões da comissão foram adotadas.

\section{O Planejamento para a adequação a Lei do Piso}

Nas palavras de Silvia e Mucci (2013), o grande desafio da gestão pública é transformar as estruturas administrativo-burocráticas em estruturas mais flexíveis e empreendedoras. E para 
isso é necessário que os gestores estejam capacitados, adotem padrões e instrumentos de gestão mais desenvolvidos, tais como o planejamento estratégico. Isso significa uma busca por eficiência e melhoria na qualidade do serviço público prestado. As autoras destacam ainda que a eficiência e eficácia da máquina pública está diretamente relacionada ao planejamento, pois este orientará a direção da gestão, como também terá reflexo na qualidade do serviço prestado

Nesse sentido foi acertada a iniciativa da gestão municipal em adotar determinados caminhos para a implantação da Lei do Piso no município: a criação de uma Comissão representativa, portanto, democrática, que pesquisou experiências em outros municípios, como também levantou o diagnóstico da realidade da rede do magistério público municipal, e ainda, realizou consultas junto aos maiores interessados na execução do trabalho, que são os professores.

Oliveira (2006), por sua vez, afirma que a distância entre o planejamento e a execução é uma das primeiras falhas da Administração Pública no Brasil. Pois, geralmente não basta existir um bom plano e orçamento para que se tenha a garantia que a execução será bem sucedida. Ainda que exista um acompanhamento técnico paulatino durante a execução do plano, não há garantia de sucesso. Assim, alerta o autor que o "resultado de um processo de planejamento, incluindo sua implementação, tem que ser visto como uma série de eventos aparentemente simples, mas que dependem de uma cadeia complexa de interações recíprocas para que obtenham o resultado esperado, e muitas vezes esta cadeia não pode ser prevista ou controlada." (p. 277, 278).

Assim, quando a Administração Municipal faz o diagnóstico da quantidade de professores a ser contratada, previsão de aposentadorias até o ano de 2018, realizou, na verdade, a preparação para as ações seguintes, que foram: contratação de professores através da convocação dos remanescentes do concurso realizado em 2013, e realização do processo seletivo para contratação de professores em regime temporário.

Porém, importante ressaltar que o anúncio da realização de outro concurso público já para o ano de $2018^{2}$, indica, a insuficiência os dois mecanismos mencionados no parágrafo anterior para suprir a necessidade de profissionais. É possível concluir que ou houve mal dimensionamento da necessidade de profissionais para implantação da reserva de carga horária,

\footnotetext{
${ }^{2}$ Concurso da prefeitura de Feira de Santana vai oferecer 150 vagas. Disponível em: https://www.acordacidade.com.br/noticias/193950/concurso-da-prefeitura-de-feira-de-santana-vai-oferecer-150-vagas.html 
que seriam 610, ou a quantidade de professores que pediriam aposentadoria até 2018 foi subestimada.

Assim, é preciso compreender as palavras de Oliveira, (2006), quando afirma que planejamento é um processo de decisão política que depende de informações precisas e

transparência. É, portanto, um exercício contínuo de aprendizagem com os erros e acertos, e não apenas a realização de um bom plano, dividindo-o em sequências temporais, alocação de recursos financeiros e tentativa de antecipação do futuro.

Planejamento exige acompanhamento contínuo da execução, inclusive com o objetivo de confirmar ou revisar o diagnóstico inicial. Nesse sentido, o fato da conclusão da reserva de carga horária no município ter sido prorrogada de 2017, conforme planejamento inicial, para 2020, após dificuldades financeiras da Administração, pode confirmar que houve precipitação da proposta inicial da Comissão, que previu a adequação a Lei do Piso em um período de apenas três semestres. Mas, por outro lado, também revela maturidade dos atores envolvidos no processo, pois reanalisaram e aceitaram um novo planejamento.

Assim, o planejamento governamental é considerado uma ação que prepara o Estado para a implantação das políticas públicas escolhidas, e a necessidade de redefinir seus caminhos, sem perder de vista seus objetivos, conforme a situação em tela, demonstra mérito da gestão e dos atores sociais envolvidos.

\section{Considerações finais}

A Lei do Piso representa um considerável avanço na regulamentação e melhoria do trabalho do professor da rede pública de ensino no Brasil. Ainda assim, a sua efetivação exigiu expressivo esforço dos professores, sindicatos e gestores públicos, inclusive através de ações judiciais.

A adequação da rede pública municipal de Feira de Santana à lei ainda não foi ocorreu completamente, o que demonstra a complexidade desse processo, porém ficou exposto que os acertos observados nessa caminhada se devem ao trabalho em conjunto da Administração e demais atores sociais.

A análise de experiências em outros municípios, diagnóstico da rede local, inclusive com estimativa de professores aptos a se aposentarem em um período de três anos, indicação e 
realização de concursos foram ações acertadas. Por outro lado, insuficientes, haja vista a necessidade de realização de outro concurso público, como também a prorrogação do prazo para finalização da adequação a Lei do Piso.

Desta forma, foi possível perceber a partir do presente processo de adequação da rede municipal de ensino de Feira de Santana a Lei do Piso, que o devido e necessário planejamento das ações, exige do gestor público a disposição para o diálogo, o aproveitamento dos recursos humanos e técnicos disponíveis, o estabelecimento de um diagnóstico preciso da realidade, e ainda, captar e aprender com as experiências externas, solidificar objetivos e estratégias para alcança-los, sem, entretanto, eximir-se de acompanhar a execução do planejamento, inclusive, dispondo-se a rediscuti-lo, quando necessário.

\section{Referências Bibliográficas}

BENINI, É., de Faria, M. S., Novaes, H. T., \& Dagnino, R. (2012). Gestão pública e sociedade: fundamentos e políticas públicas de economia solidária. São Paulo: Outras Expressões;

\section{BRASIL. Constituição Federal de 1988;}

BRASIL. Estatuto da criança e do adolescente: Lei federal nº 8069, de 13 de julho de 1990;

BRASIL. Lei de Diretrizes e Bases da Educação Nacional. Lei número 9394, 20 de dezembro de 1996;

BRASIL. Presidência da República. Casa Civil. Lei no 11.494 de 20/06/2007;

BRASIL. PALÁCIO DO PLANALTO. Lei no 11.738, de 16 de julho de 2008;

CARDOSO Jr, J. C. (2011). Planejamento governamental e gestão pública no Brasil: elementos para ressignificar o debate e capacitar o Estado (No. 1584). Texto para Discussão, Instituto de Pesquisa Econômica Aplicada (IPEA);

Estudo sobre a lei do piso. Ministério da Educação; Conselho Nacional de Educação - Câmara de Educação Básica. Em:< http://portal.mec.gov.br/index.php?option=com_docman\&view=download\&alias=10241estudo-sobre-lei-piso-salarial\&Itemid=30192>;

FEIRA DE SANTANA. Prefeitura Municipal. Decreto Municipal $\mathbf{n}^{\circ} \mathbf{9 . 2 3 4 / \mathbf { 1 4 }}$, de 15 de maio de 2014; 
NAHMIAS, P. D. S. (2014). A IMPORTÂNCIA DO PLANEJAMENTO PARA A GESTÃO PÚBLICA. Revista Científica FACPED, 5(5);

OLIVEIRA, J. A. P. de. Desafios do planejamento em políticas públicas: diferentes visões e práticas. RAP. Rio de Janeiro, 40(1):273-88, Mar./Abr. 2006;

SALDANHA, Clézio. Introdução a gestão Pública. 2 ed. São Paulo . Saraiva. 2006;

SALLES, H. D. M. (2010). Gestão democrática e participativa. Florianópolis: Departamento de Ciências da Administração/UFSC;

SILVA, W. C. D., MUCCI, C., BAETA, O. V., \& ARAÚJO, D. S. (2013). O planejamento estratégico na administração pública: um estudo multicaso. Revista de C. Humanas. Viçosa, 13(1), 90-101.

Como citar este artigo (Formato ABNT):

ROSA, Marcos da Silva da. mplantação da Lei 11.738/2008 - Lei do Piso - na Rede Municipal de Ensino de Feira de Santana: A Dimensão do Planejamento na Gestão Pública. Id on Line Revista Multidisciplinar e de Psicologia, 2018, vol.12, n.41, p.15-30. ISSN: 1981-1179.

Recebido: 21.05.2018

Aceito: 04.06 .2018 